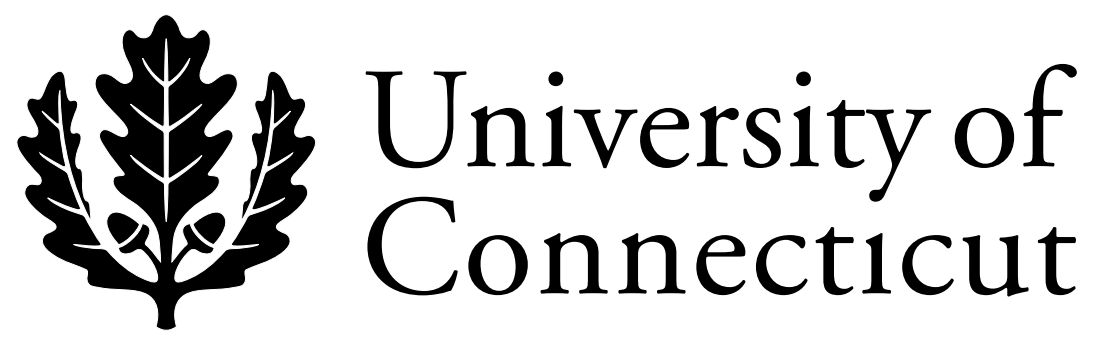

Department of Economics Working Paper Series

\title{
Should Tort Damages Be Multiplied?
}

Keith N. Hylton

Boston University

Thomas J. Miceli

University of Connecticut

Working Paper 2002-45

May 2002

341 Mansfield Road, Unit 1063

Storrs, CT 06269-1063

Phone: (860) 486-3022

Fax: (860) 486-4463

http://www.econ.uconn.edu/ 


\begin{abstract}
The notion that damages should be multiplied by the reciprocal of the probability of punishment has been around since Bentham and is one of the basic lessons of the law and economics literature. However, the simple 1/p multiplier turns out be inapplicable in the civil damages setting. The multiplier that brings about first-best deterrence must be chosen by striking a balance between the supply of lawsuits and the need to internalize costs. Moreover, given the costs of litigation, a multiplier that minimizes overall social costs (in contrast to achieving first-best deterrence) may need to be set at a level that effectively bars many claims. This paper derives optimal damage multipliers for a costly civil litigation system and examines the conflicting implications of deterrence and social cost minimization as objectives in the design of an optimal multiplier. An empirical application suggests that the first-best deterrence multiplier for the tort system is roughly equal to two.
\end{abstract}




\section{Introduction}

The notion that damages should be multiplied to make up for uncertainty in punishment has been around at least since Bentham. ${ }^{1}$ The traditional account of the optimal multiplier is straightforward: if $p$ is the probability of liability, then $1 / p$ is the multiplier that should be applied to the damage judgment. If damages are multiplied by $1 / p$, then the injurer's expected damage judgment will internalize the social loss due to his conduct.

This simple notion of the optimal multiplier has been developed further in the law enforcement context starting with Becker (1968), and later refinements. ${ }^{2}$ However, no one has worked out the optimal damages multiplier for the private litigation context. That is the goal of this paper.

To be precise, this paper has two goals. First, it seeks to derive optimal damage multipliers for a costly legal system. Second, it aims to examine the conflicting implications of deterrence and social cost minimization as objectives in the design of an optimal multiplier.

The first goal, the specification of the optimal damage multiplier, is easy to justify and presumably uncontroversial. Several recent articles have approached the optimal multiplier issue from various perspectives. Polinsky and Shavell (1999), examining punitive damages, argue that the optimal damages multiplier is simply the reciprocal of the probability of liability. Their analysis, consistent with Bentham, sees multiplying damages by the reciprocal of the probability of liability as necessary to offset the dilution in deterrence that results from uncertainty in the imposition of liability. Easterbrook (1985) argues that the uncertainty in detection provides the only good rationale for multiplying antitrust damages. Craswell (2000) shows that the effects of uncertain liability on deterrence are complicated, diluting deterrence in some instances while enhancing deterrence in others, and concludes that there is no general case for multiplying damage awards by a factor greater than one. Though coming from different perspectives, these articles are consistent with the traditional approach that takes uncertainty in enforcement as the key determinant of the optimal multiplier - i.e., the " $1 / p$ approach" to the optimal multiplier.

However, there are drawbacks in the $1 / p$ approach to the multiplier. While it may be useful in Becker's law enforcement context to treat the probability of apprehension (a component of the probability of punishment) as uniform and exogenous, this approach is less useful in the litigation context. The probability of litigation (a component of the probability of liability) differs among classes of litigant (securities class actions, malpractice) and probably within each class of litigant, depending on the relationship between the expected award and the cost of litigation. ${ }^{3}$ An implementable approach to

\footnotetext{
${ }^{1}$ Bentham (1781)

${ }^{2}$ Polinsky and Shavell (1979). For criticism of the multiplier policy from a behavioral perspective, see Sunstein, Schkade, and Kahneman (2000).

${ }^{3}$ Shavell (1982).
} 
optimal damage multipliers should be capable of specifying the functional relationship between the probability of litigation, on one hand, and variables such as the expected award and cost of litigation on the other. Moreover, in view of this relationship the multiplier should be set in a way that balances the supply of lawsuits with the need for internalization. For example, if initially only one out of ten injury victims sue, and setting the multiplier at ten results in all victims suing, costs would be over-internalized because everyone would collect ten times damages. In short, rather than treating the probability of liability as exogenous, an optimal damages framework should treat it as endogenous, a function of the factors that determine liability. ${ }^{4}$

In this paper, uncertainty in the imposition of liability is not exogenous. It results from the fact that litigation is costly. We do not assume that the plaintiff has difficulty in detecting the injurer. Rather, some victims fail to sue in this model because litigation is costly, an inescapable fact of the real world. The term "litigation cost" should be understood broadly to cover all costs that might deter some victims from filing suit. This includes the cost of paying for an attorney, and less obviously the opportunity cost of time absorbed by litigation, the psychological stress of litigation, and the costs that result because litigation tends to rupture certain relationships (e.g., employer and employee).

Although we assume detection is certain, the uncertain detection model can be viewed as a special case of the model in this paper. Uncertain detection is a special case of the litigation cost model in which the victim must incur some cost in order to detect the injurer. The perspective adopted here is arguably more general. Taking litigation costs into account naturally generates uncertainty in litigation. Second, in view of the importance of litigation costs, any serious effort to specify optimal damage awards should take them into account.

The second goal of this paper, to examine the conflicting implications of deterrence and social cost minimization, is intended to provoke debate or at least to raise questions. We distinguish two types of optimal multiplier, an optimally deterring (or optimal deterrence) multiplier and a socially optimal multiplier. The optimally deterring multiplier brings about first-best deterrence, given costly litigation. In other words, if the injurer's failure to take care imposes a loss of $\$ 1200$ on society, which is the sum of a direct harm to the victim of $\$ 1000$ and the victim's expected litigation cost of $\$ 200$, then the optimally deterring multiplier induces the injurer to take care whenever his cost of care is less than $\$ 1200$. Alternatively, one can say that the optimally deterring multiplier treats the victim's lawsuit as a natural byproduct of the injury and seeks to internalize to the injurer the full social costs of his conduct. ${ }^{5}$ In contrast, the socially optimal multiplier minimizes the sum of injuries, injury avoidance costs, and litigation costs.

We show that the optimally deterring multiplier is greater than the socially optimal multiplier. This implies that first best deterrence is never optimal under a

\footnotetext{
${ }^{4}$ Using this information, a punishing authority could specify optimal multipliers for different classes of litigant.

${ }^{5}$ For an intuitive, ethical argument for treating the victim's litigation cost as part of the injurer's harm, see Abel (1987)
} 
multiplier regime. Moreover, we show that the optimally deterring and socially optimal multiplier levels diverge as the cost of litigation increases. The reason is simple. As litigation becomes more costly, the optimally deterring multiplier increases because it forces the injurer to pay for the victim's cost of litigating, which is also increasing. In contrast, the socially optimal multiplier declines because as litigation becomes more expensive, it becomes less likely that the deterrence benefit provided by an additional lawsuit will outweigh its cost. Once the deterrent value of the marginal lawsuit dips below its cost, the social planner will set the multiplier less than one and may continue to push it down to zero in order to discourage additional lawsuits.

For simplicity, we focus on the case of strict liability - we consider negligence in the appendix. Since simple closed-form solutions for the two optimal multipliers are not available, we ran simulations to compare the multipliers in terms of their responses to changes in the ratio of damages to litigation costs. The optimally deterring multiplier is always greater than one and grows as the ratio of the cost of litigation to the harm increases. In contrast, the socially optimal multiplier can be less than one, and falls toward zero as the ratio of the litigation cost to the harm increases. The simulations suggest that it is unlikely that a treble damages rule, the standard multiplier observed in antitrust, could be socially optimal. ${ }^{6}$

Using data from two of the RAND Corporation's studies of civil litigation, we made rough estimates of the optimally deterring multiplier for the tort system overall, auto torts, and medical malpractice. The data suggest that the overall optimal deterrence multiplier should be roughly two - a "double damages" rule. The optimal deterrence multiplier for auto torts, which account for half of total tort claims, ${ }^{7}$ is also roughly two. The data do not suggest a strong case, on optimal deterrence grounds, for multiplying medical malpractice damages. Of course, our estimates should be taken as preliminary, and largely as a suggestion for future research.

The normative question generated by this paper is whether society should prefer the socially optimal multiplier to the optimally deterring multiplier. While the socially optimal multiplier maximizes social wealth, it does so, in some cases, by barring some victims from bringing suit. The socially optimal multiplier enhances social wealth when the deterrent value of the lawsuits that are barred is less than their additional litigation costs. In simpler terms, the socially optimal damages regime allows injurers to harm people without having to pay the entire cost of the harm when the losses suffered by victims are too small to justify the expenses of a trial. The optimally deterring multiplier

\footnotetext{
${ }^{6} \mathrm{We}$ are examining the standard accident model in which lapses of care raise the likelihood of injuries. We do not focus explicitly on intentional injuries, though one could argue that intentional injuries are simply special cases of the model we examine. Intentional harms present a more difficult issue in the case where the injurer's conduct is inefficient under all circumstances. If the cost of care for every potential injurer is always less than the expected harm to a victim, then an efficient rule would bar the injurer's activity. Although the internalizing penalty would be sufficient as a deterrent in this case, there is no economic reason to prefer the internalizing penalty to an even greater penalty level (perhaps infinite). See Becker (1968). For an application to the litigation context, see Hylton (1998).

${ }^{7} 1986$ RAND study, executive summary, at $\mathrm{x}$.
} 
does not allow this to occur: it sets the penalty at a level that internalizes the full social costs of harmful conduct to injurers.

The socially optimal multiplier would be chosen by a social planner that seeks to minimize social costs. An alternative approach, the Aristotelian corrective justice framework, would make the correction of wrongs the highest priority of the legal system. The optimally deterring multiplier would be chosen under any plausible corrective justice framework.

Part II presents a simple numerical illustration of the two types of multiplier and a discussion of related literature. Part III presents the model. Part IV discusses extensions of the model to the case of negligence. Part V presents an empirical application, using data from two RAND studies. Part VI reviews the results and discusses implications for the legal system.

\section{The Conflict between Deterrence and Social Cost Minimization: An Example and Some Related Literature}

In this section we elaborate on the relationship between the optimally deterring damage level and the socially optimal damage level, and we show the corresponding damage multipliers. As we noted earlier, the optimally deterring multiplier internalizes the social costs of the injurer's conduct, while the socially optimal multiplier minimizes the sum of injuries, injury avoidance costs, and litigation costs.

To see the difference between the two, consider a simple example, based on Shavell (1982b). Suppose the injurer can choose to take care or not to take care. If he takes care, the probability of an injury is .25 . If he does not take care, the probability of an injury is .75. The loss to the victim is $\$ 100$. The cost of taking care is $\$ 20$. Taking care is socially desirable because the total social cost when the injurer takes case is $\$ 20+$ $(.25)(\$ 100)=\$ 45$, while the total social cost when the injurer does not take case is $(.75)(\$ 100)=\$ 75$.

Rather than comparing the total social cost when the injurer takes care to the total social cost when he does not, an alternative is to compare the social benefit from care to its cost (the Hand formula approach). In this case, the social benefit from care is the expected value of avoided harms, $(.75-.25)(\$ 100)=\$ 50$, while the cost of care is $\$ 20$. Since the social benefit from care exceeds the cost of care, care is socially desirable.

However, the injurer will not take care without the threat of a lawsuit. This is easy to see, because if the victim cannot sue to collect compensation for his injury, the cost to the injurer of taking care is $\$ 20$, and the cost to the injurer of not taking care is $\$ 0$. Since lawsuits deter careless conduct, we can say that the social benefit from deterrence, or deterrence benefit, is the expected value of avoided harms net of the avoidance cost, $\$ 50-\$ 20=\$ 30$. The cost of "deterrence" is simply the expected total cost of litigation. 
Suppose liability is strict and the cost of litigation is $\$ 61$ for either party. Since $\$ 100>\$ 61$, the victim will definitely sue if injured. Given this, the real social cost of failing to take care is $(.75-.25)(\$ 100+\$ 122)=\$ 111$. The injurer's marginal liability, however, is $(.75-.25)(\$ 100+\$ 61)=\$ 80.5$. In this case, the optimally deterring damage multiplier, $m_{d}{ }^{*}$, equates $m_{d}{ }^{*}(\$ 80.5)=\$ 111$, and is therefore $m_{d}{ }^{*}=1.38$.

But is $m_{s}{ }^{*}=1.38$ the socially optimal multiplier? Consider the total social cost when the victim does not sue, and when the victim does sue. When the victim does not or, for some reason, cannot sue, the total social cost is $(.75)(\$ 100)=\$ 75$. When the victim does sue, the total social cost is $(.25)(\$ 222)+\$ 20=\$ 75.5$. Since society is better off if the victim does not sue, the socially optimal multiplier should be such that $\left(m_{s}{ }^{*}\right)(\$ 100)<\$ .61$, implying that $m_{s}{ }^{*}<.61$. As long as this holds, no victim will sue, and society will be better off than under the regime in which victims sue and injurers take care. As this numerical example shows, the optimally deterring and socially optimal damage multipliers may not be the same.

Instead of comparing the total social cost when the litigation is permitted and when it is not, consider comparing the deterrence benefit to the cost of deterrence (litigation). Recall that the deterrence benefit in this case is $\$ 30$. The expected total cost of litigation is $(.25)(\$ 122)=\$ 30.5$. Since the deterrence benefit is less than the cost of litigation, social costs are minimized by prohibiting lawsuits.

For comparison, consider the corresponding additive adjustments to the compensatory damage level. To internalize all of the victim's harm, we would increase the victim's damage award by an amount equal to the victim's cost of litigation, $\$ 61$. This is the additive adjustment that would correspond to the optimally deterring multiplier of 1.38. In contrast, the socially optimal additive adjustment removes the victim's incentive to sue. Thus, the socially optimal additive adjustment in this case is to subtract some amount greater than \$39 from the victim's award.

Now, let us link this example to the literature, in order to clarify this paper's contribution. Shavell (1982b) showed that the private and social incentives to sue diverge, and thus it may be optimal to bar suits in cases where there is a private incentive to sue. This is illustrated in our numerical example.

Polinsky and Rubinfeld (1988) show that the optimal level of liability under strict liability may be greater or less than the compensatory level, depending on the productivity of care. The productivity of care is determined by the extent to which care reduces the expected level of damages. If care is not sufficiently productive, they show, the optimal level of liability may be less than the compensatory level. The Polinsky and Rubinfeld paper can be viewed as a generalization of Shavell (1982b). The case in which it is optimal to bar lawsuits happens to be the case in which the marginal deterrence benefit is below the marginal cost of litigation (Hylton 2002).

Indeed, if care is productive in the sense that the marginal deterrence benefit exceeds the marginal litigation cost at levels of liability below the optimum, the optimal 
damage level is equal to compensatory damages plus the victim's cost of litigation (Hylton, 2002). If care is not productive in this sense, the optimal damage level will be lower, and may be zero (prohibition of all lawsuits). In our numerical example, care is not productive because the deterrence benefit is $\$ 30$, and the marginal litigation cost is $\$ 30.5$. The socially optimal damage award is any level less than $\$ 61$, which is obviously less than the compensatory level.

Generalizing, the socially optimal and optimally deterring damage levels will be the same when care is productive, in the sense just defined. When care is not productive, the socially optimal damage level will be less than the optimally deterring damage level.

These results clearly have implications for optimal damage multipliers, but they do not translate easily - hence the need for the analysis that follows. If care is unproductive at all damages levels, then it follows from Shavell (1982b) that lawsuits should be prohibited. In this case the socially optimal damages multiplier is zero.

How should the multiplier be set when care is productive, in the sense that the deterrence benefit is greater than or equal to the expected litigation cost? One simple approach is to use a multiplier equal to the sum of the compensatory award and the cost of litigation divided by the compensatory award. Thus, if the compensatory award is $\$ 100$, and the victim's cost of litigation \$20, the optimal award level could be achieved by using a multiplier of 1.2. The drawback to this solution is that the multiplier would be individual-specific; that is, it would depend on every individual's damage award.

We consider below uniform multipliers, which have the advantage of being useful for comparison with statutorily-set multipliers, such as the treble damages rule of antitrust. We consider both the optimally deterring and socially optimal multipliers.

\section{Model}

All injurers and victims are risk neutral, and only injurers can take care to reduce the risk of an accident. ${ }^{8}$ (Thus, the model is one of unilateral care.) If an injurer takes care, the probability of an accident is $q$, while if he does not take care, the probability is $p$, where $p>q>0$. Let $x$ be the injurer's cost of care, which will generally vary across injurers.

The dollar loss to victims in the event of an accident is $v$, which is unaffected by the injurer's care choice but varies across victims. Injurers do not know the value of a particular victim's $v$, but they know its distribution across the population of potential victims, which is given by $H(v)$. Thus, the expected damage that a randomly chosen victim will experience in the event of an accident is

$$
E(v)=\int_{0}^{\infty} v d H(v)
$$

\footnotetext{
${ }^{8}$ The model is based on Hylton (1990a, 1990b).
} 
Both injurers and victims incur a cost if the victim of an accident files a suit for damages. Let $c_{v}$ be the victim's cost of filing suit, and let $c_{i}$ be the injurer's cost of trial.

The presence of litigation costs results in underdeterrence under both strict liability and negligence rules (Hylton, 1990a). Strict liability underdeters for two reasons. First, victims whose damages are less than the cost of filing suit (i.e., those for whom $v<c_{v}$ ) do not file, so injurers ignore those damages, and second, injurers do not account for the litigation costs of those victims who do file suit.

For simplicity, we will focus on strict liability in the text and deal with the negligence case in the appendix. We will first derive the optimally deterring (or full internalization) multiplier, and then the socially optimal multiplier.

\section{A. Optimally Deterring Multiplier}

Let $m_{d}$ be the optimally deterring multiplier under strict liability. Thus, an accident victim will file suit if $m_{d} v \geq c_{v}$, or if

$$
v \geq c_{v} / m_{d}
$$

It follows that, in the event of an accident, the probability of a suit is $1-H\left(c_{v} / m_{d}\right)$. The injurer's expected cost of taking care is thus

$$
x+q \int_{c_{v} / m_{d}}^{\infty}\left(m_{d} v+c_{i}\right) d H(v)
$$

while his expected cost of not taking care is

$$
p \int_{c_{v} / m_{d}}^{\infty}\left(m_{d} v+c_{i}\right) d H(v)
$$

The injurer will take care if (3) is less than (4), or if

$$
x<(p-q) \int_{c_{v} / m_{d}}^{\infty}\left(m_{d} v+c_{i}\right) d H(v) .
$$

Now consider the social condition for care. If the injurer takes care, the expected social costs are

$$
x+q\left\{E(v)+\left[1-H\left(c_{v} / m_{d}\right)\right]\left(c_{i}+c_{v}\right)\right\} .
$$

The expected social costs if the injurer does not take care are 


$$
p\left\{E(v)+\left[1-H\left(c_{v} / m_{d}\right)\right]\left(c_{i}+c_{v}\right)\right\} .
$$

Care is socially desirable if (6) is less than (7), or if

$$
x<(p-q)\left\{E(v)+\left[1-H\left(c_{v} / m_{d}\right)\right]\left(c_{i}+c_{v}\right)\right\} .
$$

Comparison of (5) and (8) shows that when $m_{d}=1$, strict liability underdeters for the reasons noted above.

Optimal deterrence is achieved by setting $m_{d}$ such that the right-hand sides of (5) and (8) are equal. After some manipulation, we obtain the following equation for $m_{d}$ :

$$
m_{d} \int_{c_{v} / m_{d}}^{\infty}\left(v-\frac{c_{v}}{m_{d}}\right) d H(v)=E(v) .
$$

Call the left-hand side of this equation $F\left(m_{d}\right)$. Note that $F(0)=0$ and

$$
F^{\prime}=\int_{c_{v} / m_{d}}^{\infty} v d H(v)>0 .
$$

The determination of the optimal value of the multiplier, denoted $m_{d}{ }^{*}$, is shown graphically in Figure 1.

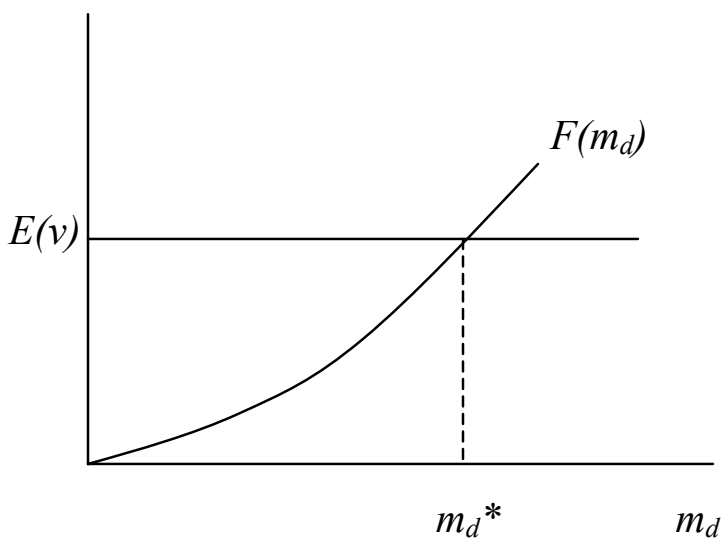

Figure 1. 
Note that, since

$$
F(1)=\int_{c_{v}}^{\infty}\left(v-c_{v}\right) d H(v)<E(v),
$$

it follows that that $m_{d}^{*}>1$ for $c_{v}>0$. Further,

$$
\frac{\partial F}{\partial c_{v}}=-\left[1-H\left(c_{v} / m_{d}\right)\right]<0
$$

which implies that, as expected, $m_{d}{ }^{*}$ is increasing in $c_{v}$.

To gain an intuitive sense of the function of the optimally deterring multiplier, note that (9) can also be expressed as:

$$
m_{d}=\frac{E(v)+\left[1-H\left(c_{v} / m_{d}\right)\right] c_{v}}{\int_{c_{v} / m_{d}}^{\infty} v d H(v)}
$$

Of course, this is not a reduced form since the right-hand side is a function of $m_{d}$. However, it is clear, as was the case with (9), that the optimal multiplier $m_{d}{ }^{*}>1 .{ }^{9}$ This is due to two factors: (1) the fact that injurers ignore victims' litigation costs (captured by the second term in the numerator), and (2) the fact that not all victims file suit (captured by the fact that the denominator is less than $E(v)$ ). The optimal deterrence multiplier is equal to the ratio of the total loss suffered by victims to the portion of the injury loss compensated through litigation. Since litigating victims will be compensated for their losses, the denominator cancels when multiplied by the average compensatory award, and the numerator guarantees full internalization of the social loss.

\section{B. Socially Optimal Multiplier}

Whereas the optimally deterring multiplier takes litigation as given and aims to internalize all of the external costs generated by the injurer's failure to take care, the socially optimal multiplier does not take litigation as given. The socially optimal multiplier minimizes the sum of injury costs, injury avoidance costs, and litigation costs. If the cost of litigation exceeds its deterrence benefits, the social cost minimization approach leads to a prohibition of litigation.

\footnotetext{
${ }^{9}$ Moreover, one can show that there is a unique optimal multiplier, based on (13). To see this, let $Z\left(m_{d}\right)$ represent the right hand side of (13). The sign of $Z^{\prime}\left(m_{d}\right)$ is equal to the sign of $\left\{m_{d}-Z\left(m_{d}\right)\right\}$. Thus, if $m_{d}<$ $Z\left(m_{d}\right), Z\left(m_{d}\right)$ is decreasing. This gives a unique fixed point $m_{d}{ }^{*}$. We will take advantage of this property in our discussion of empirical implications.
} 
Based on the informal discussion of Part II, it is straightforward to state the verbal formula for the socially optimal multiplier. The socially optimal multiplier equates the marginal social benefit from deterrence with the marginal cost of litigation.

To derive the socially optimal multiplier, we will start with the objective function. The objective can be expressed as the minimization of the sum of injuries, injury avoidance costs, and litigation costs. Alternatively, we can express the objective as the maximization of the net social benefit from deterrence, which is the difference between the deterrence benefit and the total litigation cost, where the deterrence benefit is equal to avoided harms net of the cost of care. To remain consistent with the discussion of Part II, we will use the latter expression of the objective.

Assume $x$, the cost of care, varies across individuals according to the probability distribution $G(x)$. The net social benefit from litigation can be expressed as

$$
G\left(x_{i}\right)\left[(p-q) E(v)-E\left(x \mid x<x_{i}\right)\right]-\left[G\left(x_{i}\right) q+\left(1-G\left(x_{i}\right)\right) p\right]\left(1-H\left(c_{v} / m_{s}\right)\right)\left(c_{v}+c_{i}\right)
$$

where $x_{i}$ is the level of precaution cost at which the injurer is indifferent between taking care and not taking care. On the basis of the preceding discussion, $x_{i}$ is equal to the right hand side of (5) (with a multiplier of $m_{s}$ ). The first expression in (14) is the deterrence benefit from litigation and the second expression is the expected cost of litigation.

The socially optimal multiplier sets the marginal deterrence benefit equal to the marginal cost of litigation. Although there is no simple closed-form solution for the socially optimal multiplier, one can show that the socially optimal multiplier satisfies

$$
\begin{aligned}
G_{m}\left(x_{i}\right)\left[E(v)+\left(1-H\left(c_{v} / m_{s}\right)\right) c_{v}-\right. & \left.\left(1-H\left(c_{v} / m_{s}\right)\right) m_{s} E\left(v \mid v>c_{v} / m_{s}\right)\right] \\
= & -H_{m}\left(c_{v} / m_{s}\right)\left[G\left(x_{i}\right) q+\left(1-G\left(x_{i}\right)\right) p\right]\left(c_{v}+c_{i}\right)
\end{aligned}
$$

where the subscript $m$ denotes the derivative with respect to that variable. The left hand side is the change in the probability an injurer takes care (as the multiplier increases) multiplied by the difference between the externalized loss for each injury and the internalized portion of that loss. As long as this expression is positive, the deterrence benefit from an additional lawsuit is positive. The right hand side, which is positive, is the change in the probability of a lawsuit multiplied by the expected cost of litigation.

The social optimality condition suggests that the multiplier level is not increased to the point that the social gains from deterrence are exhausted. Indeed, the following proposition is implied.

Proposition: In a costly legal system, the socially optimal multiplier is less than the optimally deterring multiplier. In other words, the socially optimal level of the multiplier will not internalize all of the social costs of the injurer's conduct. This implies that first-best deterrence is never optimal under a multiplier regime. 
This follows from observing closely the left hand side of the optimality condition. Exhausting deterrence gains would require setting the left hand side equal to zero, which results in the multiplier expression in (13); that is, the optimally deterring multiplier. Since (15) implies that the left hand side should be positive, $m_{s}$ must be less than the expression in (13), all else equal. It follows, then, that the socially optimal multiplier is less than the optimally deterring multiplier.

This result differs from the case of an additive adjustment to damages - that is, where the damage award is increased by the addition of some fixed amount. In that case, the condition that determines the socially optimal level of liability - equating the marginal deterrence benefit of additional liability to the marginal litigation cost - happens to be satisfied when the additive adjustment is equal to the victim's cost of litigation (Hylton, 2002). The reason for this is that all victims sue when the damage award is equal to the victim's loss plus the victim's cost of litigation. Since all victims sue, all social costs are internalized and the marginal deterrence benefit is driven to zero. In addition, the marginal litigation cost is driven to zero - because when every victim sues, increasing liability will not increase the probability of an additional lawsuit.

The full internalization or first-best deterrence outcome will never be socially optimal in the multiplier context. The reason is that one never reaches the point at which every victim has an incentive to file suit. For example, if the cost of litigation is $\$ 100$ and the multiplier is set at 100 , victims who suffer a loss of less than one dollar will not have an incentive to bring suit under the multiplier regime. Increasing the multiplier, therefore, always encourages additional litigation. Since the marginal litigation effect of increasing the multiplier is always positive, the socially optimal multiplier will never be set at a level that exhausts the social benefits from deterrence.

\section{Model Simulation}

The equations derived in the previous part of this paper do not yield simple closed-form solutions for the optimal multiplier expressions. We therefore ran simulations of the model in order to see how the optimal deterrence and socially optimal multipliers behave as the ratio of damages to litigation costs changes. We assumed that the distribution of precaution costs, $G(x)$, and the distribution of losses, $H(v)$, were both exponential probability functions. The exponential parameter for $H, \lambda_{h}$, was assumed to be one, and the exponential parameter for $G, \lambda_{g}$, was assumed to be 1 for the first simulation and 4 for the second. Since the exponential parameter is equal to the reciprocal of the mean of the distribution, this is equivalent to assuming that the average injury loss is $\$ 1$. For precaution costs, we assumed an average of $\$ 1$ in the first simulation and $\$ 0.25$ for the second. In addition, we assumed that the probability of loss when the injurer does not take care is .80 , and the probability of loss when the injurer does take care is .20. Under these assumptions, the average avoided loss due to caretaking is $(.8-.2)(1)=.6$. 
The simulation results appear in Figure 2 below. The horizontal axis shows the levels at which the cost of litigation was set. For example, 2 on the horizontal axis means that $c_{v}=c_{i}=\$ 2$. Since the average injury loss is $\$ 1$, one can interpret the points on the horizontal axis as the ratio of the cost of suit to the average injury loss.

Figure 2 shows that the optimal deterrence multiplier starts at a value slightly greater than one (for $c_{v}>0$ ) and increases with a slope of roughly 1.6 as the ratio of the litigation cost to the average injury loss increases. In contrast, the socially optimal multipliers rise initially and then fall as the cost of litigation increases. This is an intuitive result, given that the difference between the marginal deterrence benefit and the marginal litigation cost falls as the cost of litigation increases.

Figure 2 also shows that as precaution becomes more productive (because the difference between the average injury loss and average precaution cost increases), the socially optimal multiplier increases. This is also intuitive, because as precaution becomes more productive, the potential social gain from liability increases.

Although the socially optimal multiplier values shown in Figure 2 do not rise much above 2 , we obtained higher values by running the simulation with smaller values for the average cost of precaution (e.g., $\lambda_{g}=8$ ). Still, in all of the simulations we observed the same pattern as shown in Figure 2 - initially a rise in the socially optimal multiplier followed by a decline. 
Multiplier comparison

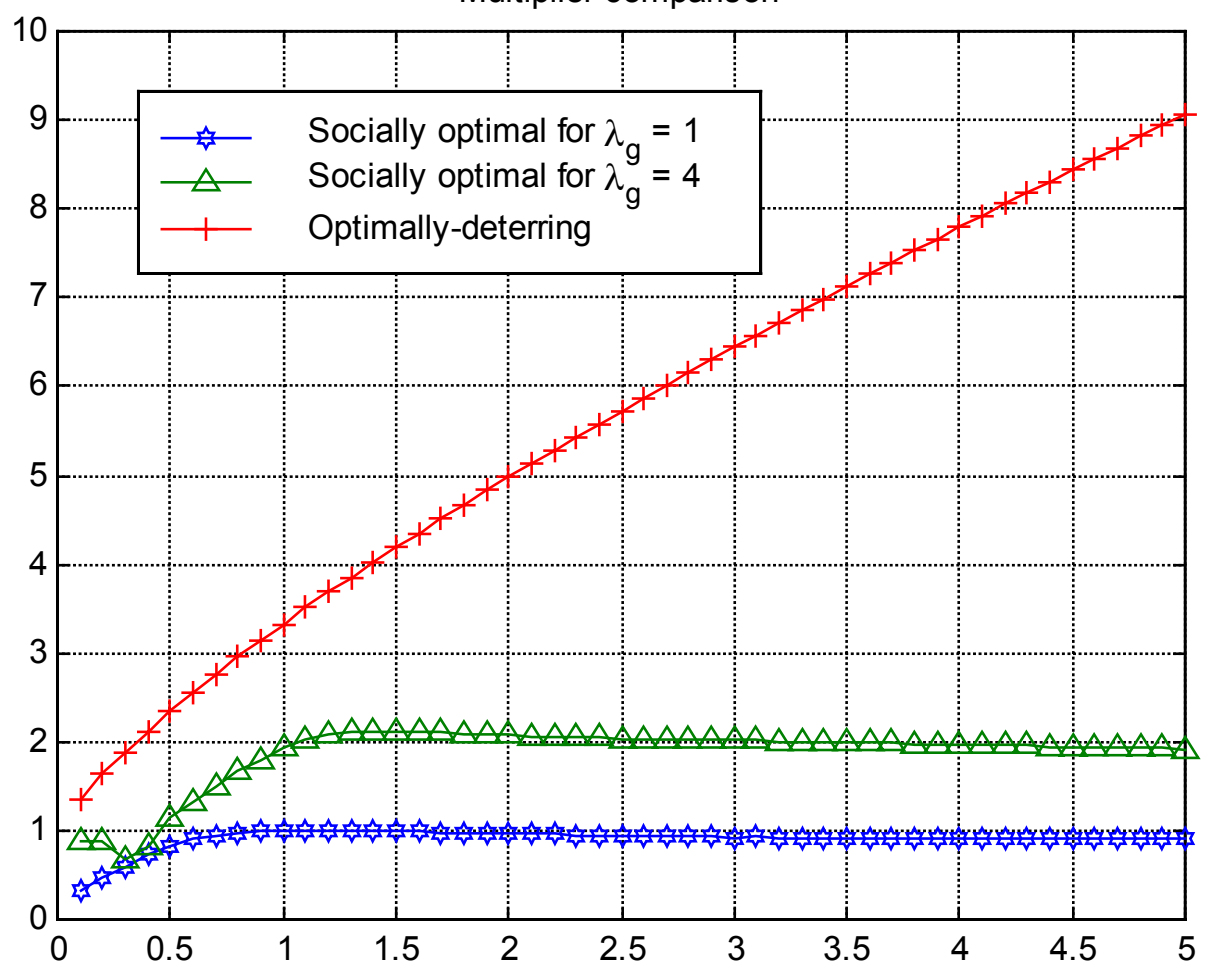

Figure 2.

\section{Extensions}

\section{A. Strict Liability versus Negligence Multipliers}

To this point we have dealt with strict liability. The results can be extended to the negligence rule, which (under the Hand rule) holds the injurer liable only if the injurer failed to take care and injurer's cost of precaution is less than the avoidable expected harm (i.e., $x<(p-q) E(v)){ }^{10}$ The negligence case is interesting because one can argue that most legal standards rely on principles of "reasonableness" that are captured in the negligence test. Most legal tests in tort law apply reasonableness formulations that require balancing costs and benefits of the injurer's conduct. Similarly, antitrust applies a "rule of reason," adapted from the common law, which involves a balancing of costs and benefits of potentially anticompetitive conduct.

We can show that the optimally deterring multiplier under negligence is greater than the optimally deterring multiplier under strict liability. The explanation requires several steps (see the Appendix for a formal derivation). First, note that you need to induce over-compliance with the negligence standard in order to guarantee first-best or optimal deterrence in the presence of costly litigation. This is true because the Hand rule does not account for litigation costs. First-best deterrence, given costly litigation,

${ }^{10}$ United States v. Carroll Towing, 159 F.2d 169, 173 (2 ${ }^{\text {nd }}$ Cir. 1947). 
requires injurers to take care whenever the cost of care is less than the sum of the avoidable expected harm and the expected cost of litigation. This level is care is greater than that required by the negligence standard.

Second, once the multiplier is set at a level that induces over-compliance with the negligence standard, the only actors who will be forced to pay damages are those who have been held liable erroneously by the court. Why? All actors for whom the cost of taking care is less than the avoidable harms will take care in this regime, and therefore will not be held liable under the negligence standard. The only actors who can be held liable are those who did not take care. Since, by assumption, we are considering the over-compliance outcome, these actors are within the group for whom the cost of care exceeds the avoidable harms. For simplicity, let us call them "actually non-negligent actors." Actually non-negligent actors will be held liable (deemed negligent) under the negligence standard only when the court errs.

Third, since the actually non-negligent are the marginal actors in this regime, the multiplier must be set to induce first-best care on their part. This can be accomplished by making them pay, in expectation, the same amount as would the marginal actor under strict liability. But they will be held liable only in the instances in which the court commits a "false conviction" (type-2 error). In order to bring about first-best deterrence within this group of actors, then, the optimally deterring negligence multiplier should be set equal to the strict liability multiplier divided by the probability of a false conviction.

This appears to be a harsh remedy. Actors who comply with the law are effectively punished because of the peculiar effect of the negligence standard. It provides the right incentives to the subgroup of actors who might be held liable under it, and virtually exempts the remaining actors from liability. In order to provide the right incentives to the remaining actors, the penalty must be set at an extremely high level. Moreover, as courts become more accurate, the multiplier must increase as well. For example, if courts are so accurate that the probability of a false conviction is only two percent, then the optimally deterring multiplier under negligence is fifty times the optimally deterring multiplier under strict liability.

The remedy may not be as harsh as first appears, though. Grady (1994) argues that for negligence cases involving non-durable precaution, the probability of a false conviction is quite high. The reason is that courts are incapable, in the non-durable precaution context, of determining whether the defendant's precaution was efficient in the typical case. ${ }^{11}$ If, as Grady suggests, negligence operates in a manner similar to strict liability in areas involving non-durable precaution, then the optimal deterrence multiplier under negligence will be roughly the same as that under strict liability.

As for the socially optimal multiplier under negligence, the lesson is largely the same as that under strict liability. The same principle that determines the socially optimal

\footnotetext{
${ }^{11}$ If a driver who should look at the road four times every minute looks only twice during one minute, and causes an accident, it would be impossible for a court to determine whether the driver's overall level of care was efficient.
} 
multiplier under strict liability determines the socially optimal multiplier under negligence, which is to set the multiplier at a level that equates the marginal benefit from deterrence to the marginal cost of litigation (see equation 15). Although we did not run simulations of the socially optimal negligence multiplier, we see no reason to believe that they would differ, in some general and important sense, from the results for the strict liability multiplier. ${ }^{12}$ On one hand, the marginal deterrence benefit from increasing the multiplier is diminished in the negligence case because as the multiplier increases, compliance with the negligence standard increases, reducing the likelihood of a plaintiff victory, and dampening the incentive to file a claim. For the same reason the marginal cost of litigation should be diminished in the negligence case because the effect of an increase in the multiplier is partially offset by the reduction in the probability of a plaintiff victory. Since both the marginal benefit and marginal cost functions shift down, as one switches from strict liability to negligence, it is difficult to predict any clear change in the level of the socially optimal multiplier.

\section{B. Compliance versus Optimal Deterrence}

Once we start to think about optimal multipliers in the negligence context, one question we immediately confront is whether we should shift our focus from optimal care to compliance with the law. In real courts, people are concerned about whether the actor complied with the legal standard, not whether his care was socially optimal. The negligence standard requires the actor to take care if his precaution cost is less than the foreseeable incremental losses. For simplicity, we will refer to compliance with the negligence standard as "reasonable" care. If actors exercise reasonable care, then they are in compliance with the negligence standard.

It is easy to determine the damages multiplier that guarantees reasonable care under strict liability. Actors will exercise reasonable care under strict liability if the expected litigation cost of the injurer equals the expected losses of victims who fail to bring suit. If the expected litigation cost of the injurer equals the expected losses of nonsuing victims, then lawsuits effectively internalize the direct losses suffered by victims, which induces reasonable care on the part of injurers. In this case, the multiplier that guarantees reasonable care under strict liability is equal to one. If the expected litigation cost of the injurer is less than the expected loss of non-suing victims then the multiplier that guarantees reasonable care under strict liability will be greater than one, and conversely. If $m_{c}$ represents the multiplier that guarantees reasonable care, then under strict liability,

$$
m_{c}=\frac{E(v)-\left[1-H\left(c_{v} / m_{c}\right)\right] c_{i}}{\left[1-H\left(c_{v} / m_{c}\right)\right] E\left(v \mid v>c_{v}\right)}
$$

\footnotetext{
${ }^{12}$ Shavell (1982b) observed that the divergence between the private and social incentive to sue under negligence is similar to that under strict liability.

${ }^{13}$ This equation is obtained by equating the right hand side of (5) with $(p-q) E(v)$ and solving for $m$.
} 
This equation suggests that the reasonable care multiplier under strict liability can be interpreted as the ratio of "total losses not internalized by the injurer's own litigation costs" to "loss internalized through lawsuits." To simplify, we will refer to this ratio below as the "defendant's cost internalization ratio."

Now, consider the negligence rule. As Craswell (2000) suggests, it is not clear that we need to multiply damages under the negligence rule in order to guarantee compliance with the negligence standard. The reason is that the negligence rule already has a sort of built-in multiplier. Whereas the incremental harm risk connected to the injurer's conduct is $p$ - $q$, the incremental liability risk under negligence, in the absence of judicial error, is $p$. Since, under negligence, the incremental liability risk is usually greater than the incremental harm risk, the negligence standard operates as if it multiplied damages in each case. This suggests that the multiplier necessary for reasonable care may be less than one under the negligence rule.

Of course, in the negligence setting, one has to make sure that the multiplier is at least at the level that induces care on the part of those for whom the cost of care is less than avoidable losses $(x<(p-q) E(v))$. At the same time, the multiplier must be less than the level that induces care on the part of those for whom the cost of care exceeds avoidable losses $(x>(p-q) E(v))$. In other words, we are interested in lower and upper bounds on a multiplier that would guarantee reasonable care under the negligence standard.

If we let $w=$ the probability the injurer will be found negligent, $\theta_{l}=$ the probability of a false finding of non-negligence (or type- 1 error), and $\theta_{2}=$ the probability of a false finding of negligence (or type- 2 error), then the lower bound on the multiplier that guarantees reasonable care under negligence is determined by ${ }^{14}$

$$
m_{c}=\frac{E(v)-\left[1-H\left(c_{v} / w m_{c}\right)\right] c_{i}}{\left[1-H\left(c_{v} / w m_{c}\right)\right] E\left(v \mid v>c_{v} / w m_{c}\right)}\left(\frac{p-q}{p\left(1-\theta_{1}\right)-q \theta_{2}}\right)
$$

The last term in (17) is the ratio of the incremental harm risk to the incremental liability risk, which is likely to be less than one. This suggests that if the injurer's litigation cost internalizes victim losses to the same degree as it does under strict liability, then the minimum multiplier necessary to guarantee reasonable care under the negligence standard will be less than the reasonable care multiplier under strict liability. The reasonable care multiplier under negligence can be interpreted as the product of the defendant's cost internalization ratio and the ratio of incremental harm to incremental liability risk.

\section{Empirical Application}

Can we determine empirically whether damages should be multiplied, and if so, by how much? In 1986, the RAND Corporation's Institute for Civil Justice published a

\footnotetext{
${ }^{14}$ This equation is obtained by equating the right hand side of (A3) with $(p-q) E(v)$ and solving for $m$.
} 
monograph titled "Costs and Compensation Paid in Tort Litigation," which includes data that could be used, in conjunction with this analysis, to get some sense of how the tort system functions as a mechanism for internalizing the losses caused by injurers.

\title{
A. Overall Tort System
}

Table 1 shows RAND's assessment of the costs and compensation levels for the tort system overall. The total compensation estimates shown include compensation for judgments in lawsuits and settlements of lawsuits.

Table 1

\author{
COMPENSATION PAID IN COMPARISON WITH TOTAL COSTS OF \\ TORT LITIGATION TERMINATED IN STATE AND FEDERAL \\ COURTS OF GENERAL JURISDICTION IN 1985
}

(In $\$$ billion)

\begin{tabular}{lcccc}
\hline Type of Expenditure & Plaintiffs & Defendants & Courts & Total \\
\hline Total compensation & $20.7-25.1$ & $20.7-25.1$ & NA & NA \\
Total costs of litigation & $7.0-8.7$ & $8.0-10.0$ & 0.5 & $15.5-19.2$ \\
Net compensation & $13.7-16.4$ & NA & NA & $13.7-16.4$ \\
Total expenditure & NA & $28.7-35.1$ & 0.5 & $29.2-35.6$ \\
\hline
\end{tabular}

Source: 1986 RAND study, Table S.3, at ix.

The figures in Table 1 can be used as aggregate estimates for some of the terms that appear in the various multiplier expressions derived in this paper. For example, the defendant's litigation costs can be taken as an aggregate estimate of $\left[1-H\left(c_{v}\right)\right] c_{i}$, and the amount of compensation paid can be taken as an estimate of the amount of the total direct injury internalized through lawsuits, $\left[1-H\left(c_{v}\right)\right] E\left(v \mid v>c_{v}\right){ }^{15}$

The 1986 RAND study does not provide an estimate of the total direct loss to tort victims. However, in 1991 RAND published a report titled "Compensation for Accidental Injuries in the United States." The 1991 RAND study estimates the total monetary cost of nonfatal accidents to be $\$ 175.9$ billion. The $\$ 175.9$ billion figure is the sum of $\$ 97.9$ billion in "medical bills and other expenses directly related the accident," and $\$ 78$ billion in lost earnings due to the accident. ${ }^{16}$ The 1991 RAND study does not provide a specific year for this figure, but most of the data on which this estimates was based was collected in the late 1980s $(1987-89) .{ }^{17}$ The $\$ 175.9$ billion figure is an

\footnotetext{
${ }^{15}$ For simplicity, we use the strict liability results derived earlier in this paper. This seems appropriate as an aggregate or system-wide multiplier. The negligence multiplier, derived in the appendix, requires more information, and would seem to be appropriate in the case in which the negligence rule operates in all disputes and the probability of a false conviction is low.

16 1991 RAND study at 103.

${ }^{17}$ See Appendix B of 1991 Rand Study, page 179.
} 
underestimate of the total monetary cost because it excludes costs for fatal accidental injuries. $^{18}$

We can use the multiplier expressions derived earlier in this paper to say whether the existing multiplier of one is too large or too small under some of the criteria developed. Consider, first, the optimal deterrence criterion. Recall that equation (13), which provides an intuitive expression for the optimal deterrence multiplier, shows that the optimal deterrence multiplier is equal to the ratio of the total loss (direct harm plus victim litigation costs) to the internalized (through lawsuits) portion of that loss. To be precise, if we let $Z\left(m_{d}\right)$ represent the ratio of the total loss to the internalized loss, then the optimal deterrence multiplier, $m_{d}{ }^{*}$, satisfies $Z\left(m_{d}{ }^{*}\right)=m_{d}{ }^{*}$. Moreover, given the properties of (13), if we choose some arbitrary $m_{d}{ }^{0}$ such that $m_{d}{ }^{\circ}<Z\left(m_{d}{ }^{\circ}\right)$, we know that $m_{d}{ }^{0}$ is less than the optimal deterrence multiplier. ${ }^{19}$

It follows, then, that if a multiplier of one were appropriate on optimal deterrence grounds, then the ratio of the total loss to the internalized loss should be equal to one. In fact, given the existing multiplier of one, the ratio of the total loss to the internalized loss is

$$
\frac{\$ 175.9+\$ 8}{\$ 23}=7.9
$$

The existing multiplier of one is apparently too low from an optimal deterrence perspective. Assuming the properties of equation (13) apply, a multiplier of 7.9 would be too large for optimal deterrence purposes. ${ }^{20}$ If we move the multiplier up from one, the ratio of the total victim loss to the internalized victim loss should fall. The optimal deterrence multiplier is therefore between 1 and 7.9. Taking the mid-point as the proxy, the optimal deterrence multiplier for the whole tort system appears to be roughly 4.5 . In other words, this analysis suggests that if damage awards were multiplied by 4.5 , injurers would be forced to bear the full social losses due to their conduct.

The multiplier necessary to guarantee reasonable care, specified in (16), is equal to the ratio of portion of the victim's direct loss that is not effectively internalized by the injurer's defense costs to the internalized portion of the victim's direct loss. We referred to this earlier as the "defendant's cost internalization ratio." The numerator of this ratio

\footnotetext{
${ }^{18}$ One way to correct this underestimate is to work backward from the total compensation data. The 1986 RAND study puts total tort compensation at roughly \$23 billion. The 1991 RAND study puts total tort compensation at $\$ 15.7$ billion, the lower figure reflecting the exclusion of wrongful death, property damage only claims, and most occupational illness and toxic exposure claims. See RAND (1991) at 198. If we assume one third of the difference is captured by the wrongful death claims, and that all accidental deaths are compensated through lawsuits, then the upward adjustment for fatal accidental injuries is roughly $\$ 2.6$ billion. This would bring the estimate of the total direct harm to $\$ 178.5$ billion. Since the adjustment is not substantial, we will use the 1991 RAND estimate in the text.

${ }^{19}$ This is because the sign of the slope of $Z(m)$ is the same as the sign of $\{m-Z(m)\}$, see supra note 9 ..

${ }^{20}$ Again, recall the argument of note 9 , supra. Plugging in the data, when $m=1, Z(m)=7.9$. Since, by the argument of note $9, Z(m)$ is decreasing, the optimal deterrence multiplier, which requires $m_{d}=Z\left(m_{d}\right)$, must be less than 7.9.
} 
is the total direct loss less injurers' litigation costs. Using $\$ 175.9$ billion as the estimate of the total direct harm and the figures from Table 1, the defendant's cost internalization ratio is

$$
\frac{\$ 175.9-\$ 9}{\$ 23}=7.3 \text {. }
$$

This suggests, again using the properties of equation (13), that the existing multiplier of one is too low to guarantee reasonable care. Taking the midpoint between one and 7.3 as the estimate, the reasonable care multiplier suggested by this is roughly 4 . Defense costs are too low to effectively internalize the direct harms of tort victims who fail to bring claims.

Now, even though the total direct harm figure does not include fatal injuries, one might argue that it is biased upward because it includes losses that are covered by liability insurance. We have in mind: (1) workers compensation payments, (2) employer disability, and (3) instances in which the liability insurer compensates the victim in the absence of a lawsuit. In these cases, the liability insurance premiums may effectively internalize the direct harms to injurers, and we would not see this internalization by simply looking at compensation through lawsuits.

The 1991 RAND study reports that roughly $\$ 35$ billion was transferred (on an annual basis) through worker's compensation and employer disability programs. We have no figures for the amount transferred through settlements by insurers in the absence of the filing of a claim. Reflecting the prevalence of no-fault, some 63 percent of the total compensation for auto torts reflects payments made in the absence of the filing of a lawsuit. ${ }^{21}$ In contrast, in medical malpractice, only 10 percent of the total compensation from liability insurance reflects claims paid without the filing of a lawsuit. ${ }^{22}$ Let us assume that 30 percent of the total compensation paid in liability insurance occurs without the filing of a lawsuit. This would give us roughly $\$ 10$ billion in payments made on liability claims without the filing of a lawsuit. Summing these figures we arrive at $\$ 45$ billion as the amount paid out in quick settlements.

If we treat quick settlements as equivalent to lawsuits, which seems appropriate, then the estimate of total compensation paid through lawsuits, $\left[1-H\left(c_{v}\right)\right] E\left(v \mid v>c_{v}\right)$, should be adjusted upward to $\$ 68$ billion. ${ }^{23}$ Using this figure, the adjusted optimal deterrence multiplier for the total tort system is found by examining the ratio of the total loss to the internalized loss:

$$
\frac{\$ 175.9+\$ 8}{\$ 68}=2.7
$$

\footnotetext{
${ }^{21}$ See infra, at 20 (estimating "quick settlements" for auto torts at $\$ 15.4$ billion and total compensation for auto torts at $\$ 24.4$ billion, yielding a ratio of 63 percent).

${ }^{22}$ See infra, at 21.

${ }^{23}$ This is the sum of the $\$ 45$ billion estimate for "quick settlements" and $\$ 23$ billion estimate for total compensation paid through lawsuits.
} 
Using the same reasoning as in the previous cases, this suggests that the optimal deterrence multiplier for the total tort system is roughly 2 . The reasonable care multiplier is found by examining the defendant's cost internalization ratio:

$$
\frac{\$ 175.9-\$ 9}{\$ 68}=2.4
$$

which suggests that the reasonable care multiplier is roughly 1.5 .

We should note that an alternative set of figures could be used to get us close to our adjusted multiplier estimates. The 1986 RAND study reports that a study by Tillinghast says that $\$ 68$ billion was spent on the U.S. tort system in 1984. The RAND study notes that the $\$ 68$ billion figure is higher than their high-end estimate of $\$ 35.6$ billion because it includes the cost of insurance premiums that "cover claims, lawsuits, and the operation of the insurance system."

To reach a figure that approximates total liability payments from insurers, deduct defense costs from Table 1, which are presumably included in the $\$ 68$ billion. Using $\$ 9$ billion for defense costs, this leaves us $\$ 59$ billion. If we take off eight percent for administrative costs and profit, the figure comes down to $\$ 54$ billion. This figure presumably reflects claims paid for by insurers, including those that did and those that did not enter the tort system. Since $\$ 23$ billion was paid to compensate litigating tort victims, the remaining $\$ 31$ billion can be taken as an estimate of liability payments made in the absence of the filing of a lawsuit. This is less than our estimate of $\$ 45$ billion. However, taking \$54 billion as the total internalized loss would yield an optimal deterrence multiplier estimate roughly the same as the adjusted estimate of two.

\section{B. Auto Torts}

The RAND studies allow us to take the same back-of-the-envelope approach to auto tort litigation. The aggregate litigation cost for plaintiffs in auto torts is put at $\$ 2.5$ billion in the 1986 RAND study. The aggregate litigation cost for auto tort defendants is put at roughly $\$ 2$ billion. The aggregate amount paid out in compensation for lawsuits was $\$ 9$ billion in 1985. This includes settlements and trial verdicts. The aggregate amount paid out in compensation (with or without lawsuits) was $\$ 24.4$ billion.

We are not primarily interested in the amount paid out as compensation to claimants, but in finding an estimate of the total direct loss. The 1991 RAND study reports the total direct monetary cost of motor vehicle accidents to be $\$ 37$ billion. Again, this is an underestimate because it excludes fatal accidents.

How much of the $\$ 24.4$ billion paid was internalized through lawsuits? Obviously, $\$ 9$ billion was internalized. However, of the difference, $\$ 15.4$ billion, some portion represents liability claims that were paid without the filing of a lawsuit. Since a rational insurer would not voluntarily pay unless the claim represented a credible lawsuit, 
we should treat the part of $\$ 15.4$ billion consisting of third-party liability claims paid without a lawsuit as early (or quick) settlements. To determine this portion we used the proportion of states that are effectively "fault" regimes.

As of 1989, 16 states were no-fault in the sense that they imposed thresholds that claims had to exceed before allowing access to the courts. An additional 9 states were "add-on" states, in the sense that the claimant could choose to forgo the no-fault plan and file a lawsuit instead. If we treat the 9 "add-on" states as half-no-fault, then the effective percentage of no-fault states is 42 percent. If 42 percent of states can be characterized as "no-fault," we will assume that 58 percent of the $\$ 15.4$ billion, $\$ 8.9$ billion, consists of early settlements on third-party liability claims. The remaining $\$ 6.5$ billion is assumed to represent first-party claims. Adding $\$ 8.9$ billion to the compensation paid in lawsuits changes the amount internalized through liability suits from $\$ 9$ billion to $\$ 17.9$ billion.

Recall that the optimal deterrence multiplier is equal to the ratio of the total victim costs (direct injury loss plus litigation costs) to the internalized portion of that loss (compensation paid). Evaluated at the existing multiplier, the ratio of the total loss to the internalized loss is

$$
\frac{\$ 37+\$ 2.5}{\$ 17.9}=2.2
$$

This suggests, under the reasoning of the previous discussion, that the optimal deterrence multiplier for auto torts is roughly 1.6 (i.e., the midpoint between 1 and 2.2).

The reasonable care multiplier is suggested by examining the ratio

$$
\frac{\$ 37-\$ 2}{\$ 17.9}=1.9
$$

Using the midpoint between one and 1.9 as the estimate, this suggests a reasonable care multiplier of 1.4 .

\section{Medical Malpractice}

The 1986 RAND study puts the aggregate litigation cost for medical malpractice defendants in 1985 at $\$ .6$ billion. The aggregate litigation cost for plaintiffs is roughly the same. The total compensation paid in lawsuits for malpractice in 1985 is $\$ 1.69$ billion. The total amount paid to malpractice claimants (summing amount paid in lawsuits and amount paid without a lawsuit) is $\$ 1.88$ billion.

One preliminary issue is how one should interpret the difference between the total amount paid to claimants, $\$ 1.88$ billion, and the total amount paid in lawsuits, $\$ 1.69$ billion. The difference, $\$ .19$ billion, represents medical malpractice claims that were paid without a lawsuit. In the malpractice context, these claims are likely to consist of highly credible potential lawsuits. Profit-maximizing insurers would not have an incentive to 
voluntarily pay out on claims that could not form the basis of a credible lawsuit. We should therefore view the $\$ .19$ billion paid by insurers without the filing of a lawsuit as early settlements. Under this view, the total $\$ 1.88$ billion should be treated as compensation paid in lawsuits.

Since neither the 1986 RAND study nor the 1991 RAND study provide an estimate of the total direct loss to medical malpractice victims, we had to reinterpret some of the data provided in the 1986 study to arrive at such an estimate. The study reports "losses incurred" for 1985 as roughly $\$ 3.5$ billion. This amount is equal to the sum of compensation paid out and the net change in reserves set aside for future claims.

We decided to treat losses incurred as a proxy for the direct losses to victims. After deducting 35 percent of the differential between "compensation paid" and "losses incurred" to estimate money set aside to cover litigation costs, we arrived at an estimate of direct loss of $\$ 2.9$ billion. Although this may seem large amount in comparison to "compensation paid," the literature on medical malpractice litigation suggests that the majority of potentially valid malpractice claims never materialize as lawsuits (Weiler, et al (1993). Insurers have records documenting the existence of these potential claims and set aside reserves to meet them, though probably not under the assumption that they will pay 100 percent of these claims.

Using \$2.9 billion as our estimate of the total direct loss, the optimal deterrence multiplier is suggested by the ratio of the total loss to the total internalized loss

$$
\frac{\$ 2.9+\$ .6}{\$ 1.88}=1.86
$$

Assuming, as in the previous cases, that the relationship between the multiplier and the ratio of the total to the internalized loss has properties that allow us to move step-by-step toward the solution for the optimal deterrence multiplier, the optimal deterrence multiplier for medical malpractice appears to be roughly 1.4. We will interpret this as an indication that multiplying damages is unnecessary for optimal deterrence purposes in medical malpractice.

The reasonable care multiplier is found by examining the ratio of the direct harm net of the defendant's litigation cost to the total internalized loss:

$$
\frac{\$ 2.9-\$ .6}{\$ 1.88}=1.2
$$

This ratio suggests, if we take the mid-point between 1 and 1.2 as the solution, that the reasonable care multiplier is roughly equal to one. There appears to be no clear case for multiplying damages in order to guarantee reasonable care in the medical malpractice context. The reason is that defense costs effectively internalize most of the direct monetary harm suffered by victims who fail to bring legal claims. 
These results are biased upward to the extent they ignore the fact that insurance premiums partially internalize the losses of victims who do not bring suit. However, the results are biased downward to the extent they fail to incorporate information on the claimants whose losses are too small to form the basis of credible lawsuit. Presumably insurers discount these claims and do not incorporate them as costs that must be covered by insurance premiums. We are unable to say which bias dominates.

\section{Summary and Implications}

The "multiplier principle" (" $1 / p$ approach"), that damages should be multiplied by the reciprocal of the probability of punishment, has been accepted as one of the basic lessons of the law and economics literature. The foregoing discussion explores the principle in the private damages setting, instead of the more common framework of analysis in which a public enforcement agency has to choose the optimal penalty. Our treatment points to three types of multiplier that courts could apply in the torts setting: an optimal deterrence multiplier that brings about first-best deterrence, a socially optimal multiplier that minimizes overall social costs, and a reasonable care multiplier that guarantees compliance with the negligence standard.

In theory the optimal deterrence multiplier could assume any positive value greater than one, depending on the size of litigation costs. Moreover, the optimal deterrence multiplier increases as litigation costs rise relative to the average direct harm. If the ratio of litigation costs to the average direct damage were sufficiently high, the optimal deterrence approach could be used to justify multipliers well in excess of the doubling or trebling rules observed in state and federal statutes.

In contrast, the socially optimal multiplier is always less than the optimal deterrence multiplier and falls toward zero as the ratio of litigation costs to the direct harm increases. Our simulation results suggest that the socially optimal multipliers will often be below the doubling or trebling levels, and sometimes less than one.

Our efforts to get rough empirical estimates of the optimal deterrence multipliers suggest comparatively modest levels in relation to the potentially large multiplier suggested by the theoretical analysis. The optimal deterrence multiplier for the whole tort system and for auto torts appears to be roughly two. Given that roughly half of all tort filings involve auto accidents, one should not be surprised to find that the optimal deterrence multipliers for the whole system and for auto torts are roughly equal. In contrast, the medical malpractice data suggest no need to multiply awards in order to guarantee optimal deterrence.

The optimal deterrence multipliers suggested by the empirical application are lower than one would expect on the basis of a simplistic application of the " $1 / p$ " approach. This intuitive approach would simply divide the harm by the probability of liability. Since the probability of liability cannot be greater than the probability that a suit is filed, the reciprocal of the probability of a lawsuit might be taken, under this approach, as a lower bound on the appropriate multiplier. Although the U.S. is known as a litigious 
country, the data show that claims are relatively infrequent events in relation to the base of injuries that give rise to them. The 1991 RAND study estimates that roughly one injury in ten leads to an attempt to collect liability compensation - in other words, a lawsuit probability of $.10 .^{24}$ The straightforward $1 / p$ approach would suggest a multiplier of at least 10 for the tort system, which is far too high.

The empirical application gives a new perspective on the role of insurance. Some commentators have suggested that insurance should be abolished because it dilutes incentives to take care. Others have noted that insurance enhances incentives to take care by financing the monitoring of care levels and providing signals to potential injurers that relate the price of insurance to their care levels. The empirical application in this paper suggests that a significant degree of internalization occurs directly through insurance or insurance-like (e.g., workers compensation) contracts, bypassing the courts. In the absence of such contracts, many of the injured parties would have to seek compensation through the tort system. Since litigation is costly, a substantial share of these claimants would not have an incentive to bring suit. Moreover, among the claimants who file suit, their targets would be limited to large, financially-sound (deep-pocket) entities. Given this, the insurance system plays an important role in directly internalizing and channeling costs to actors who are in the best position to control them.

The central normative question generated by this analysis is whether we should prefer the optimal deterrence to the socially optimal multiplier. The question is equivalent to asking whether we would prefer to live in a world with fewer accidental injuries but a lower standard of living. One could justify a preference for the optimal deterrence multiplier on the ground that people are risk averse, and given their risk aversion, would prefer as between the two multipliers the one that minimizes the risk of accidental injury. The ideal tort system minimizes the sum of primary (injury), secondary (risk-spreading), and tertiary (administrative and litigation) costs (Calabresi, 1970). A case could be made that the optimal deterrence multiplier comes closest to this objective.

However, the Calabresian argument for full internalization has an arbitrary feel to it. There is no way to show that people are sufficiently risk averse to justify the choice of the low-risk, safe regime. Moreover, in a world in which people are free to insure themselves against the risk of accidental injury, there is no uncontested case for compelling adoption of the safe regime. At a minimum, to justify such a choice, insurance markets must be so incomplete that the residual secondary costs are large enough to justify adoption of the low-risk regime.

Another approach to justifying a preference for the optimal deterrence multiplier is to rely on some version of the Aristotelian corrective justice framework. The corrective justice approach is equivalent to assuming an ordering of preferences in which the righting of wrongs through compensation is given the first priority. Since one is free to choose the definition of a wrong under this model, ${ }^{25}$ one could say that the injurer has

\footnotetext{
${ }^{24} 1991$ RAND study, at 120-21.

${ }^{25}$ Posner (1983) at 73-74.
} 
committed a wrong when he violates the negligence standard or some more stringent test based on "causation." 26 As between the socially optimal multiplier and the optimal deterrence multiplier, it should be clear that the corrective justice approach would choose the latter. To be sure, this approach is no less arbitrary than the Calabresian argument.

\section{Conclusion}

The notion that damages should be scaled up by dividing by the probability of punishment is one of the basic lessons from the economic analysis of law. While the idea has been developed further in the economic analysis of criminal law, relatively little effort has been applied to specifying multipliers for deterrence in the civil damages setting. This paper sets out to fill this gap in the literature. The simple " $1 / p$ " multiplier suggested by Bentham turns out to be inapplicable in the civil damages setting. The multiplier that brings about first-best deterrence must be chosen by striking a balance between the supply of lawsuits and the need for internalization of costs. Moreover, given the costs of litigation, a multiplier that minimizes overall social costs, as opposed to achieving first-best deterrence, may need to be set at a level (perhaps less than one) that effectively bars many claims.

\footnotetext{
${ }^{26}$ The "causation" standard (strict liability) is urged in Epstein (1973).
} 


\section{Appendix}

In this Appendix we examine the optimal deterrence multiplier under negligence. We will start with a review of basic results on compliance with the negligence rule.

Injurers face socially inadequate incentives for care under a negligence test based on the Hand formula (which hold the defendant negligent if he failed to take care when $x$ $<(p-q) E(v))$. As Ordover (1978) showed, when litigation is costly, equilibrium under a negligence rule must involve some injurers who fail to meet the due standard. If this were not the case, victims would never file suit (assuming the Hand test is applied without error), which would be inconsistent with injurers' compliance with the due standard. Thus, in equilibrium, some victims file suit and some injurers are found negligent. But since the standard of care set by the Hand test is too low in a world of costly litigation, injurers face inadequate incentives for care. If the Hand test is applied with error, greater compliance with the due standard is possible (indeed, some overcompliance may occur), but the equilibrium must still involve underdeterrence (Hylton, 1990b).

In view of these results, we examine the use of damage multipliers to achieve optimal deterrence when litigation is costly. Although negligence underdeters both with and without legal error, we show that use of a multiplier is feasible only when there is error. Further, the negligence multiplier, when feasible, will always be larger than the strict liability multiplier.

Assume, as in Hylton (1990a, 1990b) that the negligence standard is defined by the Hand test. In the context of the current model, this means that an injurer will be found negligent if he failed to take care and the court determines that his cost of care is less than the expected savings in damages; that is, if $x<(p-q) E(v)$. Injurers for whom this condition holds are said to be "potentially negligent."

As noted above, it will turn out that a multiplier can be used to achieve optimal deterrence under negligence only if the Hand test is applied with error (we will show this below). Therefore, let $\theta_{1}$ be the probability of a type 1 error (the probability that the court finds a negligent defendant non-negligent), and let $\theta_{2}$ be the probability of a type 2 error (the probability that the court finds a non-negligent injurer negligent). ${ }^{27}$ Although the court makes errors, we assume it is sufficiently accurate that

$$
1-\theta_{1}>\theta_{2}
$$

This says that a negligent injurer is more likely to be found negligent than is a nonnegligent injurer.

\footnotetext{
${ }^{27}$ We assume, following Png (1987), Polinsky and Shavell (1989), and Hylton (1990b), that both probabilities are constant.
} 
An accident victim will file suit under negligence if $w v m_{N}>c_{v}$, where $w$ is defined to be the probability that the injurer will be found negligent, and $m_{N}$ is the negligence multiplier. Thus, if an accident occurs the probability of a suit is $1-H\left(c_{v} / w m_{N}\right)$. We assume that, although victims do not know if a given injurer is negligent (i.e., they do not observe his care choice), they correctly perceive the probability of a negligent verdict, including the possibility of legal error. Thus,

$$
w=s\left(1-\theta_{1}\right)+(1-s) \theta_{2}=\theta_{2}+\left(1-\theta_{1}-\theta_{2}\right) s
$$

where $s$ is the probability that the injurer is truly negligent-i.e., that he is both potentially negligent and fails to take care. ${ }^{28}$

A potentially negligent injurer (one for whom $x<(p-q) E(v))$ will take care if

$$
x+q \int_{c_{v} / w m_{N}}^{\infty}\left(\theta_{2} m_{N} v+c_{i}\right) d H(v)<p \int_{c_{v} / w m_{N}}^{\infty}\left(\left(1-\theta_{1}\right) m_{N} v+c_{i}\right) d H(v),
$$

or if

$$
x<\left[p\left(1-\theta_{1}\right)-q \theta_{2}\right] \int_{c_{v} / w m_{N}}^{\infty} m_{N} v d H(v)+(p-q)\left[1-H\left(c_{v} / w m_{N}\right)\right] c_{i} \equiv A\left(m_{N}\right)
$$

An injurer who is not potentially negligent (one for whom $x>(p-q) E(v)$ ) will take care if

$$
x+q \int_{c_{v} / w m_{N}}^{\infty}\left(\theta_{2} m_{N} v+c_{i}\right) d H(v)<p \int_{c_{v} / w m_{N}}^{\infty}\left(\theta_{2} m_{N} v+c_{i}\right) d H(v)
$$

or if

$$
x<(p-q) \int_{c_{v} / w m_{N}}^{\infty}\left(\theta_{2} m_{N} v+c_{i}\right) d H(v) \equiv B\left(m_{N}\right)
$$

Note from (A3) that the incentive for care by potentially negligent injurers is reduced by an increase in both types of errors. In contrast, (A4) shows that incentives for care by injurers who are not potentially negligent are unaffected by type 1 errors but are actually enhanced by an increase in type 2 errors. This is because injurers who are not potentially negligent can never be found incorrectly non-negligent, but they do face the possibility of being found incorrectly negligent. This reduces the benefit of failing to take care.

\footnotetext{
${ }^{28}$ Since victims correctly perceive the probability of a negligent verdict, they calculate $s$ using Bayes' rule (see Hylton, 1990b). It will turn out, however, that in an efficient equilibrium, $s=0$.
} 
As under strict liability, injurers ignore the damages to victims who do not file suit as well as the litigation costs of those who do. Thus, the social condition for care under negligence is given by

$$
x<(p-q)\left\{E(v)+\left[1-H\left(c_{v} / w m_{N}\right)\right]\left(c_{v}+c_{i}\right)\right\} \equiv S\left(m_{N}\right)
$$

The objective is to set the negligence multiplier so that all injurers for whom (A5) is satisfied actually take care. Since the right-hand side of (A5) exceeds $(p-q) E(v)$, it follows that all potentially negligent injurers, as well as some who are not potentially negligent, should take care. This is true because the Hand rule, which determines potential negligence, ignores litigation costs, which increase the socially desirable level of care. Thus, in an efficient equilibrium, it must be the case that $s=0$. That is, no injurers are truly negligent according to the Hand rule. As a result, (A2) implies that $w=\theta_{2}$, which says that the only findings of negligence by the court are erroneous ones. This is a consequence of the fact, noted above, that when litigation is costly, a negligence equilibrium without legal error must underdeter (Ordover, 1978; Hylton, 1990a).

The fact that, in an efficient equilibrium, the marginal care taker must be an injurer who is not potentially negligent, implies that the relevant equation for deriving the negligence multiplier is $S\left(m_{N}\right)=B\left(m_{N}\right){ }^{29}$ After setting $w=\theta_{2}$ and rearranging, this equation can be written

$$
m_{N} \theta_{2} \int_{c_{v} / m_{N} \theta_{2}}^{\infty}\left(v-\frac{c_{v}}{m_{N} \theta_{2}}\right) d H(v)=E(v)
$$

or

$$
F\left(m_{N} \theta_{2}\right)=E(v)
$$

Comparing this equation to equation (9) in the text implies

$$
m_{S}=m_{N} \theta_{2} \text {, or } m_{N}=m_{S} / \theta_{2}
$$

Since $\theta_{2}$ is between zero and one, $m_{N}>m_{S}$. Thus, the negligence multiplier is larger than the strict liability multiplier, all else equal.

A further implication of (A7) is that

$$
\frac{\partial m_{N}}{\partial \theta_{2}}=-\frac{m_{N}}{\theta_{2}}<0
$$

\footnotetext{
${ }^{29}$ Note that $A\left(m_{N}\right)>B\left(m_{N}\right)$. Thus, in an efficient equilibrium, all potentially negligent injurers will take care as well.
} 
Thus, the negligence multiplier decreases as the probability of type 2 error increases. (See Figure 3.) This reflects the fact that type 2 errors enhance deterrence for injurers who are not potentially negligent, and therefore move the equilibrium closer to the optimum. Equation (A7) also implies that if $\theta_{2}=1$, the optimally deterring negligence and strict liability multipliers are identical. In this case, negligence in effect becomes strict liability because taking care does not act as a shield from liability.

At the other extreme, as $\theta_{2} \rightarrow 0$, the negligence multiplier becomes infinite. This reflects the fact that in a world without legal error, no injurers who are not potentially negligent can be induced to take care because they will never be found negligent by the court. Thus, the multiplier cannot be applied to them. In theory, a negligence multiplier could still improve deterrence by being set to induce all potentially negligent injurers to take care (some of whom do not do so in equilibrium), but, as noted above, this would not be sufficient to achieve optimal compliance, given that the due standard set by the Hand rule is too low (i.e., a perfect compliance equilibrium is suboptimal). Moreover, it would simply restore the problem of non-existence of an equilibrium in which there is perfect compliance.

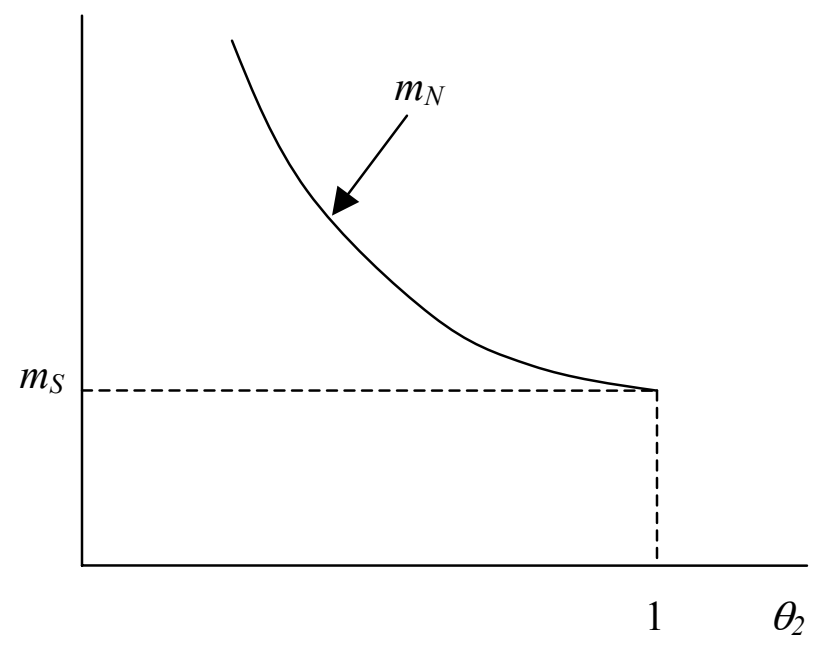

Figure 3. 


\section{References}

Richard Abel, The Real Torts Crisis - Too Few Claims, Ohio St L. J. (1987).

Jeremy Bentham, An Introduction to the Principles of Morals and Legislation (1781)

Gary S. Becker, Crime and Punishment: An Economic Approach, 76 Journal of Political Economy 169 (1968)

Guido Calabresi, The Costs of Accidents: A Legal and Economic Analysis (1970)

Richard Craswell, Deterrence and Damages: The Multiplier Principle and Its

Alternatives, 97 Michigan Law Review 2185 (1999)

Frank Easterbrook, Detrebling Antitrust Damages, 28 Journal of Law and Economics 445 (1985)

Richard A. Epstein, A Theory of Strict Liability, 2 Journal of Legal Studies 151 (1973)

Mark F. Grady, Res Ipsa Loquitur and Compliance Error, 142 University of Pennsylvania Law Review 887 (1994).

Deborah R. Hensler, et al., Compensation for Accidental Injuries in the United States, The RAND Corporation, R-3999-HHS/ICJ, 1991.

Keith N. Hylton, The Influence of Litigation Costs on Deterrence under Strict Liability and under Negligence, 10 International Review of Law and Economics 161 (1990a)

Keith N. Hylton, Costly Litigation and Legal Error under Negligence, 6 Journal of Law, Economics, and Organization 433 (1990b)

Keith N. Hylton, Punitive Damages and the Economic Theory of Penalties, 86 Georgetown Law Journal 421 (1998).

Keith N. Hylton, The Welfare Implications of Costly Litigation under Strict Liability, American Law and Economics Review (forthcoming, 2002)

James S. Kakalik and Nicholas M. Pace, Costs and Compensation Paid in Tort Litigation, The RAND Corporation, R-3391-ICJ, 1986.

I.P.L. Png, Litigation, Liability, and Incentives for Care, 34 Journal of Public Economics 61 (1987)

A. Mitchell Polinsky and Daniel Rubinfeld, The Welfare Implications of Costly Litigation for the Level of Liability, 17 Journal of Legal Studies 151 (1988) 
A. Mitchell Polinsky and Steven Shavell, The Optimal Tradeoff between the Probability and Magnitude of Fines, 69 American Economic Review 880 (1979)

A. Mitchell Polinsky and Steven Shavell, Legal Error, Litigation, and the Incentive to Obey the Law, 5 Journal of Law, Economics, and Organization 99-108 (1989)

A. Mitchell Polinsky and Steven Shavell, Punitive Damages: An Economic Analysis, 111 Harvard Law Review 869 (1998)

A. Mitchell Polinsky and Steven Shavell Journal of Law, Economics, and Organization (1989)

Richard A. Posner, The Economics of Justice (1983)

Steven Shavell, Suit, Settlement, and Trial: A Theoretical Analysis under Alternative Methods for the Allocation of Legal Costs, 11 Journal of Legal Studies 55 (1982a)

Steven Shavell, The Social Versus the Private Incentive to Bring Suit in a Costly Legal System, 11 Journal of Legal Studies 333 (1982b)

Cass R. Sunstein, David Schkade, and Daniel Kahneman, Do People Want Optimal Deterrence?, 29 Journal of Legal Studies 237 (2000)

Paul Weiler, et al., A Measure of Malpractice: Medical Injury, Malpractice Litigation, and Patient Compensation (1993) 